\title{
A rapid online survey of knowledge about COVID-19 among medical students of Nagpur
}

\author{
U U Ukey ${ }^{1}$ D S Chitre ${ }^{2}$, S K Sharma ${ }^{3 *}$
}

\author{
1,3Associate Professor, Department of Community Medicine, Government Medical College, Nagpur, Maharashtra, INDIA. \\ ${ }^{2}$ Medical Officer, Community Medicine Department, Government Medical College \& Hospital, Medical Square, Hanuman Nagar, Nagpur, \\ Maharashtra, INDIA. \\ Email: saritawadhva@yahoo.com
}

\begin{abstract}
Background: Since its beginning the year 2020 has been marked by a new global pandemic which has emerged and spread rapidly, caused by a new strain of Coronaviruses called SARS-CoV-2. It is essential in the current circumstances that medical undergraduates have adequate knowledge about COVID-19. Present study was planned to study the knowledge of medical undergraduate students about COVID-19. Materials and Methods: The present study was conducted at Government Medical College and Hospital, Nagpur located in state of Maharashtra in the central part of India. The study was carried out during March 2020. It included a survey in total 210 students from all four years of M.B.B.S. It was a rapid assessment descriptive cross sectional study. Data collection was done by a pretested, predesigned self administered questionnaire containing total questions about knowledge, causation, spread and prevention of COVID19. Descriptive statistics like percentage, mean, and SD (standard deviation) were computed for data presentation. Observations and Results: Number of male respondents was 103 and female students were 107 in number. Students from all four years of MBBS participated in the study. Good knowledge was reflected by $111(52.86 \%)$, fair knowledge was present in $83(39.52 \%)$ whereas poor knowledge was observed in only $16(7.62 \%)$ of the study participants. There was a statistically significant difference in scores of male and female respondents $(p<0.05)$. Conclusions: The study concludes that majority of the medical students had knowledge about COVID-19.

Key Words: COVID-19, Cross sectional, Knowledge, Medical students, Online, Undergraduates
\end{abstract}

*Address for Correspondence:

Dr SK Sharma, Associate Professor, Department of Community Medicine, Government Medical College, Nagpur, Maharashtra, INDIA.

Email: saritawadhva@yahoo.com

Received Date: 03/04/2020 Revised Date: 11/05/2020 Accepted Date: 23/06/2020

DOI: https://doi.org/10.26611/10111512

This work is licensed under a Creative Commons Attribution-NonCommercial 4.0 International License. (cc)) EY-NC

\begin{tabular}{|l|l|}
\hline \multicolumn{2}{|c|}{ Access this article online } \\
\hline Quick Response Code: & Website: \\
\cline { 1 - 1 } & www.medpulse.in \\
\cline { 2 - 2 } & \\
\hline
\end{tabular}

\section{INTRODUCTION}

Since its beginning the year 2020 has been marked by a new global pandemic which has emerged and spread rapidly, caused by a new strain of Coronaviruses called SARS-CoV-2. This pandemic started in Wuhan, China in December 2019, possibly due to cross-species transmission ${ }^{1}$, and involved almost every country in the world causing mostly mild upper respiratory tract symptoms and in a minority of cases lower respiratory tract infections (LRTI) called coronavirus disease-19 (COVID-19). ${ }^{2,3}$ This new disease has turned out to be a health disaster due to its physical, mental, social, economic and vocational ramifications. It is posing a bewildering array of challenges for health care services and communities at large across the world and India is no exception. Extensive and effective mitigation efforts will be required to successfully "flatten the curve" of COVID19 pandemic in India and for that health authorities will need timely and actionable data to design policies and interventions that are easily understood and relevant to beneficiaries' lives: ${ }^{4,5}$ During pandemics like that of COVID-19, healthcare systems are put under great pressure, and a shortage of healthcare providers (HCP) can drive the participation of less experienced HCP such 
as medical students. In addition, medical students are commonly referred to for healthcare advice from family and friends. ${ }^{6}$ The recent COVID19 pandemic has led to near-complete saturation and exhaustion of healthcare resources worldwide, including India. ${ }^{7}$ Tapping into the massive human resource from undergraduate medical schools could be a potential solution and many state governments in India are considering it. ${ }^{8}$ Despite the fact that most graduation school students are still in the learning phase of their career and are neither experienced nor licensed to practice, emergent circumstances may force state governments to engage them in the arduous task of volunteer -force against Covid-19. ${ }^{7}$ This calls upon the medical students to be aware about the current diseases and the patterns of which can be helpful for them to prevent themselves and others from it. Thus it is essential in the current circumstances that medical undergraduates have adequate knowledge about COVID-19. A survey on knowledge yields critical information to guide response and recovery efforts, health education, and social mobilization. It also helps to identify misconceptions prevalent about transmission and prevention and the need to prevent stigmatization. ${ }^{9}$ Simultaneously such study is also of utmost importance to appropriately assess the level of knowledge towards the disease (COVID 19 specifically here) in various subgroups of the populations with special emphasis on highly involved subpopulations including healthcare workers and students. With this background the present study was planned to study the knowledge of medical undergraduate students about COVID-19.

\section{MATERIALS AND METHODS}

The present study was conducted at Government Medical College and Hospital, Nagpur located in state of Maharashtra in the central part of India. The study was carried out during March 2020. It included a survey in total 210 students from all four years of M.B.B.S. Considering the current pandemic and lockdown situation, this study as conducted using an online questionnaire. It was a rapid assessment descriptive cross sectional study. Data collection was done by a pretested, predesigned self administered questionnaire containing total questions about knowledge, causation, spread and prevention of COVID-19. The study questionnaire was mainly based on the frequently asked questions (FAQ)s given by the ministry of health and family welfare (MOHFW). ${ }^{10}$ The study participants were provided with a link for the questionnaire through WhatsApp. Approval from the Institutional ethics Committee (IEC) was obtained regarding carrying out the study. An informed consent was obtained from the study participants for their participation in the study. The students were explained about the nature and purpose of the study. Participation in the study was kept purely voluntary. The correct responses were given a score of one and incorrect response was given a score of zero. The total scores were expressed in percentage. Score of more than or equal to $50 \%$ was considered good, that of less than $50 \%$ and more than or equal to $30 \%$ was considered fair and scores less than $30 \%$ were considered as poor. Data was obtained in the form of excel sheet. Data analysis was done with help of open epi info and descriptive statistics like percentage, mean, and SD (standard deviation) were computed for data presentation. Chi square test was applied to test the level of significance.

\section{OBSERVATIONS AND RESULTS}

In the present study, questionnaire was filled by 210 medical students. Mean age of study participants was 20.21 years with a standard deviation (Sd) of 1.05 years. Number of male respondents was 103 and female students were 107 in number. Students from all four years of MBBS participated in the study. The gender-wise details of the medical students are shown in table 1 .

Table 1: Details of the study participants

\begin{tabular}{|c|c|c|c|}
\hline Parameter & & Gender & \\
\hline Age in years & $\begin{array}{c}\text { Male } \\
\text { Number (\%)* }\end{array}$ & $\begin{array}{c}\text { Female } \\
\text { Number (\%)* }\end{array}$ & $\begin{array}{c}\text { Total } \\
\text { Number (\%) }\end{array}$ \\
\hline 18 & $4(3.88)$ & $7(6.54)$ & $11(5.24)$ \\
\hline 19 & 19 (18.45) & $22(20.56)$ & 41 (19.52) \\
\hline 20 & $30(29.13)$ & $42(39.25)$ & 72 (34.29) \\
\hline 21 & $40(38.83)$ & $27(25.23)$ & 67 (31.90) \\
\hline 22 & $9(8.74)$ & $8(7.48)$ & $17(8.10)$ \\
\hline 23 & $1(0.97)$ & $1(0.93)$ & $2(0.95)$ \\
\hline Total & $103(49.05)$ & $107(50.95)$ & $210(100)$ \\
\hline
\end{tabular}




\begin{tabular}{cccc}
\hline Year of MBBS & Male & Female & Total \\
\hline 1st & $17(16.50)$ & $12(1.21)$ & $29(13.81)$ \\
2nd & $36(34.95)$ & $46(42.99)$ & $82(39.05)$ \\
3rd & $45(43.69)$ & $44(41.12)$ & $89(42.38)$ \\
4th & $5(4.85)$ & $5(4.67)$ & $10(4.76)$ \\
\hline Total & $103(49.05)$ & $107(50.95)$ & $210(100)$ \\
\hline \multicolumn{5}{c}{ *indicates group-wise percentage }
\end{tabular}

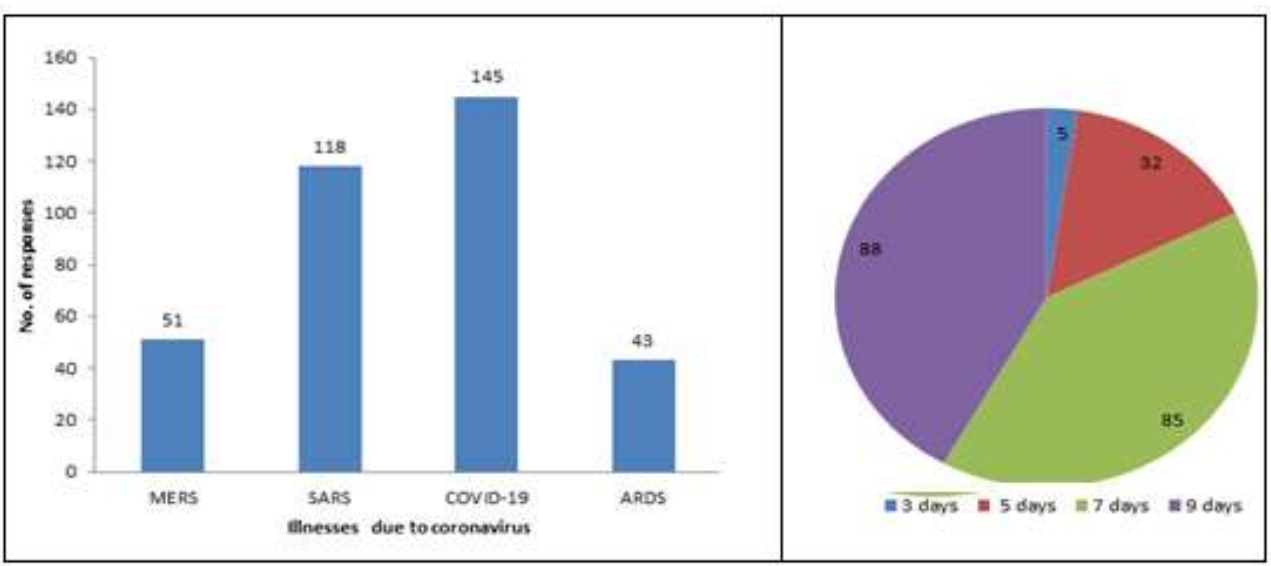

Figure 1: Respiratory illnesses that can be caused by coronaviruses in humans

Figure 2: Incubation period

The study participants were asked about illnesses that can be caused due to different coronaviruses in human beings. It was a multiple response type question. The responses to this closed ended question are depicted in figure 1.

First case of COVID 19 was detected in China was known to all (100\%) of the study participants. Commonly the incubation period for COVID-19 is 5 days. This was marked by $32(15.28 \%)$ of the study participants. The details about responses on knowledge about incubation period of COVID-19 is presented in Figure 2.

The questionnaire included questions related to knowledge about causation, symptoms, various modes of spread and prevention of COVID 19. Details of the same are shown in table 2.

Table 2: Knowledge about COVID 19

\begin{tabular}{|c|c|c|c|}
\hline Statement/Question & Correct response & Number $(n=210)$ & Percentage \\
\hline $\begin{array}{l}\text { In humans, several corona viruses are known to cause respiratory infections } \\
\text { ranging from the common cold to more severe diseases }\end{array}$ & True & 191 & 90.95 \\
\hline $\begin{array}{l}\text { It is possible to catch COVID-19 from someone who has, for example, just a } \\
\text { mild cough and does not feel ill. }\end{array}$ & True & 137 & 65.24 \\
\hline Is COVID-19 the same as SARS? & No & 112 & 53.33 \\
\hline \multirow[t]{2}{*}{ Globally the first case of COVID 19 was detected during } & December 2019 & & \\
\hline & & 126 & 60.00 \\
\hline Mode of spread of COVID-19 & $\begin{array}{l}\text { Touching contaminated } \\
\text { surface and droplets }\end{array}$ & 193 & 91.90 \\
\hline $\begin{array}{c}\text { Can humans become infected with the corona virus infection from an animal } \\
\text { source? }\end{array}$ & Yes & 106 & 50.48 \\
\hline Can you catch COVID-19 from your pet? & No & 148 & 70.48 \\
\hline \multirow[t]{2}{*}{ The most common symptoms of COVID-19 } & Fever, tiredness, dry & & \\
\hline & cough, & 133 & 63.33 \\
\hline Around 1 out of every______ people who gets COVID-19 becomes & 6 & & \\
\hline seriously ill and develops difficulty breathing. & & 36 & 17.14 \\
\hline \multirow[t]{2}{*}{ Antibiotics are effective in preventing or treating the COVID-19 } & False & & \\
\hline & & 131 & 62.38 \\
\hline \multirow[t]{2}{*}{ Is there a specific vaccine, drug or treatment for COVID-19? } & No & & \\
\hline & & 153 & 72.86 \\
\hline How should one dispose the used mask during COVID outbreak? & $\begin{array}{l}\text { Discard mask in a closed } \\
\text { bin immediately after use }\end{array}$ & 113 & 53.81 \\
\hline
\end{tabular}




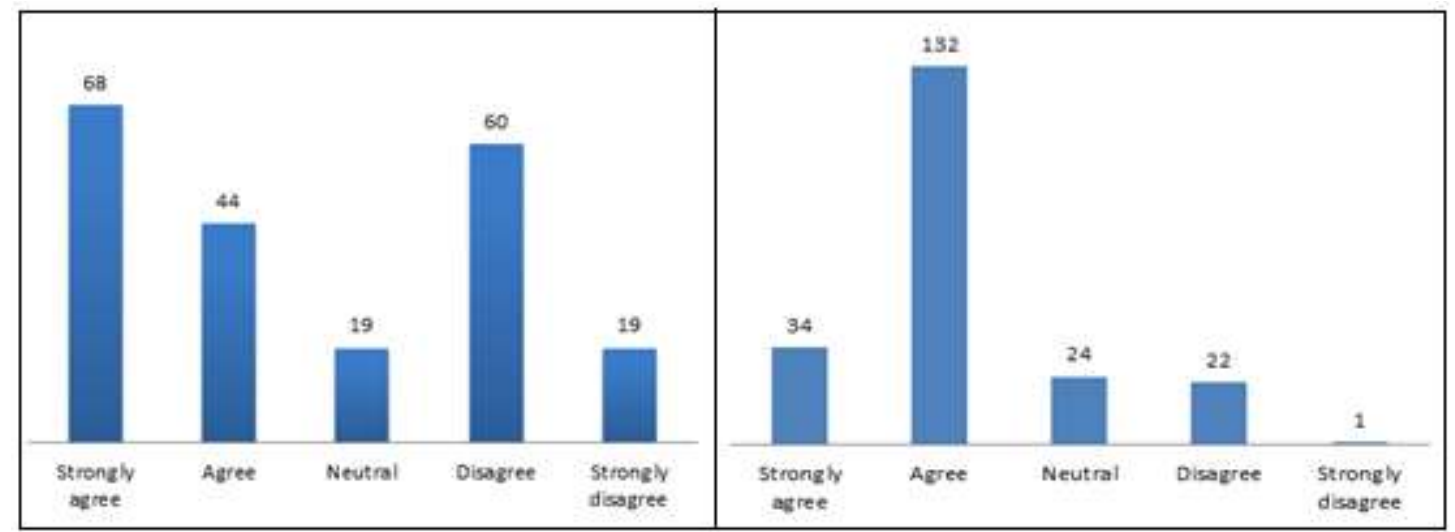

Figure 3: Opinion about asymptomatic nature of COVID-19 Figure 4: Opinion about mask usage

The study participants were asked to opine on a five point Likert scale about asymptomatic nature of COVID-19 i.e. can some people of COVID 19 become infected but do not develop any symptoms and don't feel unwell. The response to this is displayed graphically in figure 3 ahead. Similarly, an opinion was also sought on a five-point Likert scale about the compulsory usage of masks. The question asked was, should wearing mask be compulsory during COVID 19 pandemic to protect from the disease. The details of this are displayed in the form of a bar diagram in figure 4 .

Total scores of the study participants based on their correct responses were graded as good, fair and poor. Good knowledge was reflected by 111 (52.86\%), fair knowledge was present in $83(39.52 \%)$ whereas poor knowledge was observed in only $16(7.62 \%)$ of the study participants. The scores were compared with gender and year of MBBS study. The results are shown in table 3.

\begin{tabular}{|c|c|c|c|c|}
\hline $\mathrm{m}_{\mathrm{s}}$ & & Good & Fair & Poor \\
\hline \multirow[t]{3}{*}{ Gender } & Male & 63 & 33 & 7 \\
\hline & Female & 48 & 50 & 9 \\
\hline & \multicolumn{4}{|c|}{ Chi square $=6.3647, d f=2, p=0.04148^{*}$} \\
\hline \multirow[t]{3}{*}{ MBBS year } & First MBBS & 9 & 17 & 3 \\
\hline & All others & 102 & 66 & 13 \\
\hline & \multicolumn{4}{|c|}{ Chi square $=6.4642, d f=2, p=0.0394^{*}$} \\
\hline
\end{tabular}

As obvious from the table, there was a statistically significant difference in scores of male and female respondents ( $p$ $<0.05$ ). Also the knowledge of first MBBS students was observed to be significantly less in comparison with other students $(\mathrm{p}<0.05)$.

\section{DISCUSSION}

Medical students are clinicians who have responsibilities to patients and who should be allowed to fulfill their duties as such. In addition to the benefits to patients and the health care system, allowing students to participate reinforces important values, such as altruism, service in times of crisis, and solidarity with the profession. In the present study o knowledge of medical students about COVID-19, study participants from all years of MBBS participated. Majority of them were from $2^{\text {nd }}$ and $3^{\text {rd }}$ year of MBBS. Number of male and female students was almost similar. Both amounted for almost half of the study population. This distribution is similar to a study by Mohammed et al. from Nigeria. ${ }^{11}$ Most of the participants had correct knowledge that in humans several corona viruses are known to cause respiratory infections ranging from the common cold to more severe diseases. Most of them also had a correct knowledge about modes of spread of
COVID-19. Overall knowledge about the symptoms of COVID-19 was fairly good with more than half of the participants had correct knowledge about the symptoms. In addition knowledge regarding non availability of vaccine or any specific antiviral treatments against COVID-19 was present in a vast majority of the medical students i.e. approximately in above three-fourth participants. The correct knowledge about disposal of used mask was also noted among more than half the medical students. These findings are coherent with another studies. ${ }^{12,13}$ Study from Nigeria supports this finding wherein the authors explain it by quoting that high level of knowledge could be attributed to the increased publicity and effect of the pandemic on lives and livelihood. ${ }^{11}$ All the findings are a positive sign that the medical students are having an insight into the current pandemic situation and they are thus updating them with the correct knowledge. As the society looks forward onto the doctors as COVID warriors with the medical 
students as being the budding ones having knowledge about aspects of COVID is indeed a promising asset. However it was observed that knowledge about common incubation period of COVID-19 and its severity was present in very few study participants. Thus there is a need to focus on all aspects of the disease as these have a role to play in prevention of the disease. A noteworthy point is that majority of the participants had a good or fair knowledge about COVID-19, indirectly pointing towards their preparedness. Providing knowledge through authentic sources either books, journals or official websites will help the medical students in gaining an all round update on COVID-19. The medical students do not treat the patients directly. But by having a correct knowledge they can definitely treat the misconceptions about the disease. The limitations of the study need a mention. A low response rate of $23.57 \%$ can be a limiting factor of the current cross sectional study and its statements cannot be generalized. Moreover the questionnaire was a self administered one. However in spite of the limitations the current study brings out the picture of knowledge about COVID-19 among medical students specifically from the central part of India.

\section{CONCLUSIONS}

The study concludes that the study participants had a good knowledge about COVID-19. Gender and year of MBBS study was significantly associated with the findings.

\section{ACKNOWLEDGEMENTS}

The authors acknowledge the encouragement by the Dean for research. The support and guidance by the Professor and Head of Community Medicine is also greatly acknowledged. The authors are thankful to all the medical undergraduate students for participating in this study.

\section{REFERENCES}

1. Ji W, Wang W, Zhao X, Zai J, Li X. Cross-species transmission of the newly identified coronavirus 2019-nCoV. J Med Virol. (2020) 92:433-40. doi: 10.1002/jmv.25682

2. Bogoch II, Watts A, Thomas-Bachli A, Huber C, Kraemer MUG, Khan K. Pneumonia of unknown etiology in Wuhan, China: potential for international spread via commercial air travel. J Travel Med. (2020) 27:1-3. doi: 10.1093/jtm/taaa008

3. Zhu N, Zhang D, Wang W, Li X, Yang B, Song J, et al.. A novel coronavirus from patients with pneumonia in China,
2019. N Engl J Med. (2020) 382:727-33. doi: 10.1056/NEJMoa2001017

4. Acharya, Rajib and Gundi, Mukta and Ngo, Thoai and Pandey, Neelanjana and Patel, Sangram and Pinchoff, Jessie and Rampal, Shilpi and Saggurti, Niranjan and Santhya, K and White, Corinne and Francis, A. (2020). COVID-19-related knowledge, attitudes, and practices among adolescents and young people in Bihar and Uttar Pradesh, India: Study description.

5. Ioannidis, John. (2020). Coronavirus disease 2019: the harms of exaggerated information and non-evidence-based measures. European Journal of Clinical Investigation. e13223. 10.1111/eci.13223.

6. COVID-19 - Knowledge, Attitude and Practice among Medical and Non-Medical University Students in Jordan, J. Pure Appl. Microbiol., 2020; 14(1):17-24.

7. Vishwesh Agarwal ,Latika Gupta, Samira Davalbhakta,Durga Misra, Vikas Agarwal,Ashish Goel Undergraduate medical students in India are underprepared to be the young-taskforce against Covid-19 amid prevalent fears https://www.medrxiv.org/content/10.1101/2020.04.11.200613 33v2.full.pdf

8. Miller DG, Pierson L, Doernberg S. The Role of Medical Students During the COVID-19 Pandemic. Ann Intern Med. 2020 Apr 7:M20-1281. doi: 10.7326/M20-1281.

9. Jalloh, Mohamed and Robinson, Susan and Corker, Jamaica and $\mathrm{Li}$, Wenshu and Irwin, Kathleen and Barry, Alpha and Ntuba, Paulyne and Diallo, Alpha and Jalloh, Mohammad and Nyuma, James and Sellu, Musa and VanSteelandt, Amanda and Ramsden, Megan and Tracy, LaRee and Raghunathan, Pratima and Redd, John and Martel, Lise and Marston, Barbara and Bunnell, Rebecca. (2017). Knowledge, Attitudes, and Practices Related to Ebola Virus Disease at the End of a National Epidemic - Guinea, August 2015. MMWR. Morbidity and Mortality Weekly Report. 66. 1109-1115. 10.15585/mmwr.mm6641a4.

10. Detail Question and Answers on COVID-19 for Public. Ministry of health and family welfare. 2020.

11. Mohammed A, Mohammed A, Mohammed IU, Danimoh MA, Laima CH. Risk perception and willingness of medical students in North East Nigeria to Participate in Mitigating COVID 19 Pandemic. Journal of Advances in Medicine and Medical Research. 2020; 32(7): 107-114.

12. Modi PD, Nair G, Uppe A, et al.. COVID 19 Awareness among healthcare students and professionals in Mumbai metropolitan region: A questionnairre based survey. Cereus. 2020;12(4):e7514. DOI: 10.7759/cereus.7514

13. Taghir MH, Borazjani R Shiraly R.COVID 19 and Iranian medical students; asurvey on their related knowlegde,preventive behaviours and risk perception. Arch Iran Med. 2020;23(4): 249-54.

Source of Support: None Declared
Conflict of Interest: None Declared

Policy for Articles with Open Access:

Authors who publish with MedPulse International Journal of Community Medicine, Print ISSN: 2579-0862, Online ISSN: 2636-4743 agree to the following terms: Authors retain copyright and grant the journal right of first publication with the work simultaneously licensed under a Creative Commons Attribution License that allows others to share the work with an acknowledgement of the work's authorship and initial publication in this journal.

Authors are permitted and encouraged to post links to their work online (e.g., in institutional repositories or on their website) prior to and during the submission process, as it can lead to productive exchanges, as well as earlier and greater citation of published work. 